\title{
MULTIPLE HYBRID GENOTYPES OF LEISHMANIA (VIANNIA) IN A FOCUS OF MUCOCUTANEOUS LEISHMANIASIS
}

\author{
DEBBIE NOLDER,* NORMA RONCAL, CLIVE R. DAVIES, ALEJANDRO LLANOS-CUENTAS, AND \\ MICHAEL A. MILES \\ Department of Infectious \& Tropical Diseases, London School of Hygiene \& Tropical Medicine, London, United Kingdom; \\ Instituto de Medicina Tropical "Alexander von Humboldt", Universidad Peruana Cayetano Heredia (UPCH), Lima, Peru
}

\begin{abstract}
The principal agent of mucocutaneous leishmaniasis (MCL) is the South American protozoan parasite Leishmania (Viannia) braziliensis. This organism is generally considered to be clonal, that is, it does not to undergo genetic exchange. Nevertheless, apparent hybrids between several Leishmania species have been reported in the New World and the Old World. When we characterized isolates of Leishmania (Viannia) from a single focus of cutaneous leishmaniasis (CL) and MCL, we found a remarkable phenotypic and genotypic diversity, with 12 zymodemes and 20 microsatellite genotypes. Furthermore, 26 of the 59 isolates were L. braziliensis/L. peruviana phenotypic hybrids that displayed 7 different microsatellite genotypes. A hybrid genotype was the only organism isolated from 4 patients with MCL. Thus hybrids must be included among the potential agents of MCL. Despite the propensity for clonality, hybrids are also an important feature of Leishmania (Viannia) and may give rise to epidemiologically important emergent genotypes.
\end{abstract}

\section{INTRODUCTION}

Leishmaniasis is a major public health problem in much of Latin America, where Leishmania of the subgenus Leishmania are agents of visceral leishmaniasis (VL), cutaneous leishmaniasis (CL), and diffuse cutaneous leishmaniasis (DCL). The subgenus L. (Viannia), which is restricted to the New World, causes CL and metastatic mucocutaneous leishmaniasis (MCL).

In Peru, both CL and MCL are endemic. Leishmania ( $\mathrm{Vi}$ annia) braziliensis and $L$. (V.) peruviana are most frequently associated with CL, although $L$. (V.) guyanensis, L. (V.) lainsoni and L. (Leishmania) amazonensis have also been reported. ${ }^{1} \mathrm{MCL}$ is attributed to L. braziliensis. However, lesions from L. braziliensis and L. peruviana are not distinct in the early stages of CL, and species have often been incriminated on the basis of known geographical range, with $L$. peruviana found mostly in the western Andes and inter-Andean valleys and $L$. braziliensis occurring predominantly at lower altitudes in the Amazonian region. Mucosal leishmaniasis (ML), with involvement of the mucosae by contiguity from a primary lesion, has been described for all species causing CL in Peru. ${ }^{1}$ However, ML is distinct from MCL, which involves metastatic spread to mucosal sites some time after a primary infection. Control of MCL depends predominantly on passive or active case finding, diagnosis, and effective treatment. ${ }^{2}$ Dogs are commonly infected with $L$. braziliensis and/or $L$. peruviana, and they may act as a peridomestic reservoir. ${ }^{3,4}$ The sylvatic reservoir hosts of $L$. peruviana and L. braziliensis are incompletely known, although terrestrial small rodents have been implicated for some strains. ${ }^{4,5}$

Where the Amazonian forest and Andean regions meet, as in the Department of Huánuco, both $L$. braziliensis and $L$. peruviana may occur sympatrically. Leishmania (Viannia) isolates that appear to be hybrids between $L$. braziliensis and $L$. peruviana have been reported from this region of Peru. ${ }^{6}$

Herein we describe the phenotypes (obtained by multilocus

\footnotetext{
* Address correspondence to Debbie Nolder, Department of Infectious \& Tropical Diseases, London School of Hygiene \& Tropical Medicine, Keppel Street, London WC1E 7HT, United Kingdom. E-mail: debbie.nolder@lshtm.ac.uk
}

enzyme electrophoresis, MLEE), and genotypes (obtained by microsatellite multilocus typing, MLMT) of 59 isolates from the Department of Huánuco. The results show that putative hybrid phenotypes and genotypes are common. A remarkable degree of diversity is revealed, suggesting that propagation is not entirely clonal and indicative of some form of genetic exchange in the Huánuco $L$. $(V$.) population.

\section{MATERIALS AND METHODS}

Isolate collection. Leishmania were isolated in 1994-1995 from 45 humans and 14 dogs, from cutaneous lesions on the ear or nose, in villages around Huánuco City (2000-3000 m above sea level). Eleven patients had MCL, and 34 had CL. Full ethical permission was given by the Universidad Peruana Cayetano Heredia with informed consent obtained from human subjects for parasite diagnosis. Households in these areas routinely keep dogs, donkeys, pigs, and chickens. A full list of the isolate codes is available from the authors upon request.

Isolates were phenotyped and genotyped against the following $L$. (V.) reference strains: $L$. (V.) braziliensis (MHOM/ BR/84/LTB300); L. (V.) peruviana (MHOM/PE/94/LC1152; MHOM/PE/84/LC26; MHOM/PE/84/LC39); L. (V.) panamensis (MHOM/PA/71/LS94); L. (V.) guyanensis (MHOM/ BR/75/M4147); L. (V.) shawi (MHOM/BR/94/M15065); L. (V.) lainsoni (MHOM/BR/81/M6426); and L. (V.) sp. ${ }^{7}$ (ISQU/BR/86/IM2832).

Isolation and in vitro cultivation of parasites. Reference strains were retrieved from liquid nitrogen storage onto biphasic $4 \mathrm{~N}$ blood slopes. ${ }^{8}$ Peruvian stocks were dispatched from Lima on $4 \mathrm{~N}$ blood slopes and were passaged onto fresh slopes and incubated at $23^{\circ} \mathrm{C}$ upon receipt. Isolates from this first-passage culture were stored under liquid nitrogen; subsequent passages were kept to a minimum to reduce culture selection of parasite strains. Promastigote cultures were expanded in alpha-modified minimal essential medium (SigmaAldrich Ltd., Gillingham, Dorset, UK) supplemented with $10 \%$ heat-inactivated fetal bovine serum, $50 \mu \mathrm{g} / \mathrm{mL}$ gentamicin, $30 \mathrm{mM} \mathrm{NaHCO}$, $40 \mathrm{mM}$ HEPES, $20 \mathrm{mM}$ D-glucose, 4 $\mathrm{mM}$ L-glutamine, $10 \mu \mathrm{M}$ hemin, $30 \mu \mathrm{M}$ adenine, $10 \mu \mathrm{M}$ folic acid, and $10 \mu \mathrm{M}$ D-biotin (all supplements from Sigma Chemi- 
cal Co., Gillingham, Dorset, UK). Enzyme lysates were prepared from logarithmic-phase bulk cultures according to the method of Evans and others. ${ }^{8}$

Isoenzyme electrophoresis. Diversity of the Leishmania isolates was initially analyzed by MLEE using thin-layer starch gels. ${ }^{9}$ The enzymes applied were mannose phosphate isomerase (MPI, EC 5.3.1.8); glucose phosphate isomerase (GPI, EC 5.3.1.9); proline dipeptidase (PEPD, EC 3.4.13.9); phosphoglucomutase (PGM, EC 2.7.5.1); nucleoside hydrolase using 2 different substrates, inosine (NHi, EC 3.2.2.1; 2 loci: NHi1 and NHi2) and deoxyinosine (NHd, EC 3.2.2.x); 6-phosphogluconate dehydrogenase (6PGD, EC 1.1.1.44); glucose-6-phosphate dehydrogenase (G6PD, EC 1.1.1.49); esterase (ES, EC 3.1.1.1); aspartate aminotransferase (ASAT, EC 2.6.1.1); and alanine aminotransferase (ALAT, EC 2.6.1.2).

Microsatellite genotyping and DNA sequencing. Subsequent analyses involved multilocus microsatellite typing $(\mathrm{MLMT})^{10}$ and DNA sequencing. Micosatellites AC01, $\mathrm{AC} 16$, and $\mathrm{AC} 52^{11}$ were amplified from promastigote genomic DNA. The micosatellites were amplified with primers AC01F and AC01R-FAM (GAGAGGCCACCAGACACGTCAGCACAC and CCCCCTTCCTTCGCCTTCAACACCTTTAC, respectively), AC16F and AC16R-TET (CTTCTTCTCATGCTGCACGGTCTCCTCCTT and CCATGGGCGGGCTTGTTTCGTTACTTTTTA, respectively), and AC52F and AC52R-HEX (CCACCGCCGGCTTCACTAC and GCGGCAATCGTCTGGCTAAA, respectively). Reverse primers were fluorophore-labeled as indicated (PerkinElmer, Beaconsfield, UK). Amplification reactions were carried out according to a protocol modified from that of Russell and others. ${ }^{11}$ PCR amplification for each sample was done in a $10 \mu \mathrm{L}$ reaction mix containing $10 \times \mathrm{NH}_{4}$ reaction buffer $(160$ $\mathrm{mM}\left(\mathrm{NH}_{4}\right)_{2} \mathrm{SO}_{4}, 670 \mathrm{mM}$ Tris- $\mathrm{HCl}, \mathrm{pH} 8.8,0.1 \%$ Tween-20 [Bioline, London, UK]), $1 \mathrm{mM}$ (AC01, AC52) or $2 \mathrm{mM}$ (AC16) $\mathrm{MgCl}_{2}, 0.2 \mathrm{mM}$ each of dATP, dCTP, dGTP, and dTTP (Pharmacia LKB, Upsala, Sweden), 5 pmol of each primer, $0.5 \%$ formamide (v/v), 1 U of Taq DNA polymerase (Bioline), and $25 \mathrm{ng}$ of genomic DNA. PCR amplification was carried out in microtiter plates with sealed lids using the heated-lid option in an MJ Research PTC-200 Peltier thermocyler (Genetic Research Instrumentation Ltd., UK) using the following parameters: 35 cycles of $95^{\circ} \mathrm{C}$ for $30 \mathrm{~s}, 62^{\circ} \mathrm{C}$ (AC01 and AC52) or $60^{\circ} \mathrm{C}$ (AC16) for $30 \mathrm{~s}, 72^{\circ} \mathrm{C}$ for $1 \mathrm{~min}$, followed by a final extension period of $10 \mathrm{~min}$ at $72^{\circ} \mathrm{C}$. The multiplexed microsatellite products were sized on an ABI 377 automated sequencer by Genescan ${ }^{\circledR}$ and Genotyper ${ }^{\circledR}$ software (Applied Biosystems, Warrington, UK).

The AC01 products were sequenced by dye-terminator cycle sequencing and aligned using Sequence Navigator (Applied Biosystems).

Population genetics analysis. Resultant data from MLEE and MLMT were tested for genetic recombination and segregation using five population-genetics analyses: HardyWeinberg (HW) equilibrium, ${ }^{12}$ fixation index (Fis), ${ }^{12} D^{\prime}$ in$\operatorname{dex},{ }^{13}, R^{2}$ index, ${ }^{13}$ and index of association $\left(I_{\mathrm{A}}\right) \cdot{ }^{14}$

\section{RESULTS}

The isoenzyme phenotypes of the isolates were diverse. Twelve zymodemes (LON217-228) were encountered among the 59 Huánuco stocks by MLEE. One human isolate was identified as L. lainsoni, and 3 dog isolates as $L$. (V.) sp. n. ${ }^{7}$. For the remaining 55 isolates (Table 1), the enzymes GPI, G6PD, ASAT, and ALAT were monomorphic while MPI, PEPD, PGM, NHi, NHd, 6PGD, and ES were polymorphic. The 55 isolates were initially classified according to their defining MPI profile, diagnostic for L. braziliensis and L. peruviana; 25 isolates were L. braziliensis (inferred MPI genotype 1/1), 4 were L. peruviana (2/2), and 26 had a double-banded MPI profile indicative of $L$. braziliensis/L. peruviana hybrids $(1 / 2)$. Mixed cultures were excluded both by the occurrence of the same phenotype in biologic clones ${ }^{6}$ and by distribution of band intensities, including the presence of the classic triplebanded hybrid phenotype (with a central band of greater intensity) for dimeric enzymes. ${ }^{6,9}$ All putative hybrids had a triple-banded profile for the dimeric enzyme NHd. In contrast to the L. braziliensis/L. panamensis hybrids from Nicaragua, ${ }^{9}$ the Huánuco hybrids did not have the same overall phenotype (Tables 1 and 2).

Twenty multilocus microsatellite genotypes were identified, including 6 different multilocus genotypes among isolates from MCL lesions (Tables 1 and 2). Double peaks indicated heterozygosity. Twenty-three L. braziliensis/L. peruviana hybrids were heterozygous at the AC01 locus, as were many L. braziliensis. AC01 DNA sequence was obtained for all 55 isolates that generated a PCR product for the AC01

TABLE 1

Zymodeme and microsatellite genotypes of 55 Leishmania (Viannia) isolates, Huánuco, Peru

\begin{tabular}{cccccc}
\hline \multirow{2}{*}{ Species } & & \multicolumn{3}{c}{ Microsatellite genotype } & \\
\cline { 3 - 5 } & Zymodeme $^{38}$ & AC01 & AC16 & AC52 & No. of \\
isolates
\end{tabular}

Bold shows the phenotypes (zymodemes) and the multilocus microsatellite genotype associated with mucosal disease (MCL); $\mathrm{X}=$ not amplifiable; ND = not done; NS = no scorable by Genotyper ${ }^{\circledR},{ }^{*}$ Bold in parentheses shows numbers of isolates from MCL, roman numerals (I, V) show number of isolates from dogs. Reference strains used in phenotyping and genotyping were $L$. (V.) braziliensis (MHOM/BR/84/LTB300); L. (V.) peruvian (MHOM/PE/94/LC1152; MHOM/PE/84/LC26; MHOM/PE/84/LC39); L. (V.) panamensis (MHOM/PA/71/LS94); L. (V.) guyanensis (MHOM/BR/75/M4147); L. (V.) shawi (MHOM BR/94/M15065); L. (V.) lainsoni (MHOM/BR/81/M6426); and $L$. $(V$.$) sp. n. { }^{7}$ (ISQU/BR/86 IM2832). 
TABLE 2

Summary of zymodemes and multilocus microsatellite genotypes

\begin{tabular}{lccc}
\hline \multicolumn{1}{c}{ Species } & $\begin{array}{c}\text { No. of isolates } \\
\text { [MCL associated] }\end{array}$ & $\begin{array}{c}\text { No. of zymodemes } \\
\text { (10 loci) [MCL } \\
\text { associated] }\end{array}$ & $\begin{array}{c}\text { Minimum+ no. of } \\
\text { microsatellite genotypes } \\
\text { (3 loci) }[\text { MCL associated] }\end{array}$ \\
\hline L. braziliensis & $26[6]$ & $5[4]$ & $8[4]$ \\
L. peruviana & $4 *[1]$ & $1[1]$ & $2[1]$ \\
L. b/pe hybrids & $26 \dagger[4]$ & $4[1]$ & $7[1]$ \\
L. lainsoni & $1[0]$ & $1[0]$ & $1[0]$ \\
L. $($ V.) sp. n. & $3 \S[0]$ & $1[0]$ & $2[0]$ \\
Totals & $59[11]$ & $12[6]$ & $20[6]$ \\
\hline * 1 from dog; $\dagger 10$ from dog; §all from dog; $+\mathrm{X}$ and NS are not considered distinct geno-
\end{tabular}
types here (see Table 1).

locus. In most cases, the number of dinucleotide repeats from sequence analysis correlated exactly with allele size by Genotyper®. When isolates were scored as heterozygous, the superimposed downstream sequences were clearly interpretable as 2 alleles differing by number of repeats. For example, all $L$. braziliensis isolates scored using Genotyper ${ }^{\circledR}$ as 227/231 were found to have overlapping sequence reads that could be interpreted as 2 alleles differing by 2 repeats (i.e., 8 and 10), giving allele sizes that varied by 4 base pairs. Only 6 of the $L$. braziliensis/L. peruviana hybrids were heterozygous at the unlinked AC16 locus. The complexity of AC52 profiles only allowed limited allele scoring.

Five population-genetics analyses, Hardy-Weinberg (HW) equilibrium, ${ }^{12}$ fixation index (Fis) ${ }^{12} D^{\prime}$ index $,{ }^{13}, R^{2}$ index, ${ }^{13}$ and index of association $\left(I_{\mathrm{A}}\right),{ }^{14}$ were applied to the data for 58 isolates, including (due to apparent sharing of alleles) $L$. (V.) sp. n. ${ }^{7}$ but excluding L. lainsoni. The results were as follows:

1. Four of 10 polymorphic enzyme loci (MPI, ES, PEPD, and NHd) showed no significant deviation from HW equilibrium $(P>0.05$, HW exact test), whereas 4 enzyme loci (PGM, GPI, G6PD, NHi1) and both microsatellite loci (AC01, AC16) deviated from HW equilibrium (NHi2 and ASAT were monomorphic, ALAT and 6GPD had null alleles).

2. Excess heterozygosity was indicated by negative Fis values at 3 of 10 polymorphic loci MPI $(-0.133)$, NHi $(-0.425)$, NHd (-0.281), and AC01 (-0.288), whereas 4 loci showed deficits of heterozygosity, 3 of which were entirely homozygous.

3. $D^{\prime}$ indices were calculated for pairwise combinations of loci, with " 1 " denoting complete linkage and " 0 " indicating no linkage. ${ }^{13}$ Calculations were based on maximumlikelihood estimates of gametic frequencies. ${ }^{13}$ Reference to the L. major genome sequencing project indicates at least 8 different chromosomal assignments, although the loci are not yet mapped for L. (Viannia). Seven out of 13 pairwise combinations showed a value of $D^{\prime}<0.7$. Three of these pairwise values $(\mathrm{MPI} \times \mathrm{NHi1}, \mathrm{AC} 16 \times \mathrm{NHi1}$, and AC16 $\times \mathrm{NHd})$ were statistically significant $(P \leq 0.01, Q$ test). ${ }^{13}$ Corresponding $r^{2}$ values of linkage disequilibrium were lower, as is normal for this index..$^{13}$

4. The Maynard Smith index of association, $I_{\mathrm{A}}$, which assesses linkage disequilibrium over all loci, was calculated. $I_{\mathrm{A}}$ values for all enzyme loci (0.59) and for all loci (0.97) did not indicate panmixia $\left(I_{\mathrm{A}}=0\right)$. Values are comparable to those obtained with a smaller number of loci for Try- panosoma brucei populations exhibiting epidemic clonality. $^{15}$

In summary, overall the results from these tests indicated that the Huánuco L. (Viannia) population diverges from clonality or linkage disequilibrium. Firstly, the partial lack of significant deviation from HW equilibrium and, secondly, the significant $D^{\prime}$ values imply that some form of genetic exchange has occurred among the Huánuco L. (Viannia) population.

\section{DISCUSSION}

The trypanosomatids that cause human diseases (trypanosomiasis and leishmaniasis) were for many years considered to be incapable of genetic exchange, with reproduction confined to binary fission, in which one parental form divides to produce two identical offspring. Sexual dimorphism is not apparent, and chromosomes do not condense and therefore cannot be visualized. As a result, meiosis and mitosis cannot be observed directly.

Perceptions that T. brucei and Trypanosoma cruzi are entirely clonal have changed dramatically. With the aid of drugresistance markers, genetic exchange was demonstrated to occur in the tsetse fly salivary glands, both within and between the T. brucei subspecies. ${ }^{16}$ The mechanism appears to be Mendelian, with occasional aneuploid progeny. ${ }^{17}$ Dependent on the locality under study, the population genetics of $T$. brucei ranges from panmixia in some undisturbed natural hosts and habitats through epidemic clonality, to true clonality. ${ }^{15}$ Among T. cruzi populations, phylogenetic analysis revealed genetic exchange ${ }^{18}$ and hybrids were produced experimentally in the laboratory. ${ }^{19}$ The $T$. cruzi experimental hybrids were derived from mammalian cells, not from the triatomine bug vector ${ }^{19}$ (although this does not exclude occurrence of genetic exchange within the vector). The mechanism of hybridization in $T$. cruzi, involving fusion, genome erosion, and recombination, was unusual but compatible with hybrid genotypes and the extensive range of DNA content found among natural populations. Heitman ${ }^{20}$ has drawn attention to striking parallels between $T$. cruzi and the fungus Candida albicans: cell fusion in C. albicans yields tetraploid progeny, which in appropriate growth conditions undergo random chromosome loss to revert to diploidy. ${ }^{21}$

Similarly, perceptions of Leishmania as entirely clonal have been questioned by reports of several instances of naturally occurring hybrid strains, especially from the New World. On the basis of phenotypic and genotypic markers, hybrids have been described between L. braziliensis and L. panamensis in Nicaragua9; between L. braziliensis and L. guyanensis in Venezuela $^{22}$; between L. braziliensis and L. guyanensis in Ecuador $^{23}$; and between L. braziliensis and L. peruviana in Peru. ${ }^{6}$ In the Old World, L. major/arabica hybrids were described. ${ }^{24}$ Putative parental and hybrid phenotypes of the L. donovani complex (L. donovani; "L. archibaldi") occur, sympatrically in East Africa, and sequencing of housekeeping genes encoding enzymes shows mosaic characters across such strains. ${ }^{25}$ Preliminary genetic analysis suggests that genetic exchange may occur among L. tropica populations in the Middle East. ${ }^{26}$ Most recently, genetic hybrids between $L$. infantum and $L$. major have been described, from immunocompromised patients in Portugal. ${ }^{27}$ Mixed Leishmania infections occur in natural hosts and in vectors, and infections in mammals may 
last for decades, providing ample opportunities for interactions between distinct genotypes. Overall, this is substantial circumstantial evidence that an extant mechanism of genetic exchange remains to be described for Leishmania, with epidemiologic implications, for example, in the spread of emergent strains or drug resistance.

L. peruviana was recorded in the Department of Huánuco prior to the epidemic from which the isolates in this study were derived. However, prior to this epidemic, CL was seldom encountered and no cases of MCL were recorded (Llanos-Cuentas, unpublished data). It is likely that introduction of L. braziliensis ${ }^{6}$ resulted in the increased prevalence of CL, and outbreak of MCL. L. braziliensis may have been introduced by human immigration from another region or by human or canine intrusion into an unidentified sylvatic transmission cycle.

The 59 Huánuco isolates analyzed here showed a remarkable degree of isoenzyme diversity considering that they originated from such a small geographical area. L. guyanensis and L. amazonensis, previously reported from Peru, ${ }^{1}$ were not identified. However, 4 species-L. peruviana, L. braziliensis, L. lainsoni, and L. (V.) sp. n. ${ }^{7}$-were found to occur sympatrically in Huánuco. In addition, L. braziliensis/L. peruviana phenotypic hybrids were common and almost as abundant as L. braziliensis. This local prevalence of hybrid strains is reminiscent of the predominance of the genetic hybrids of T. cruzi among human cases of Chagas disease in Paraguay and adjacent regions. ${ }^{28}$ The gene encoding the enzyme MPI has recently been sequenced from both $L$. braziliensis and $L$. peruviana, and phenotypic differences have been shown to correspond with a single nucleotide polymorphism (SNP), changing a threonine to an arginine, which has been used as the basis of a PCR identification assay. ${ }^{29}$ It would be of interest to confirm that the current L. braziliensis, L. peruviana, and L. braziliensis/L. peruviana hybrid isolates, and those from a wider geographical range, conform to the predicted SNP genotypes.

It was surprising to find 4 MLEE phenotypes and 7 microsatellite genotypes among the L. braziliensis/L. peruviana hybrids. This might be a consequence of the rapid evolution of microsatellites, or it could be consistent with the occurrence of more than one hybridization event. It is very unlikely that these genotypes are explicable by mutation, with no hybridization event. By analogy, multilocus sequence typing (MLST) of the L. donovani complex has revealed multiple heterozygous sites within a gene and at several loci, with sharing of alleles within and across genetic groups: recombination, ${ }^{25,30}$ rather than mutation, ${ }^{31}$ is considered to be the most parsimonious explanation.

The majority (12) of the L. braziliensis/L. peruviana hybrids had a single genotype (Table 1 ). The expansive clonal propagation of one of the putative hybrid genotypes suggests that a hybrid agent has emerged with increased fitness relative to the parental strains, although a neutral event, such as a population bottleneck, unlikely in view of the diversity within the population, may also have been involved. One comparison of promastigote growth rates found no evidence that L. braziliensis/L. peruviana hybrids had an enhanced growth rate in vitro. ${ }^{32}$. Nevertheless, it would be of interest to compare the metastatic potential of the hybrid and nonhybrid genotypes in the hamster model of $\mathrm{MCL}^{33}$ or perhaps in the mouse ear model for dissemination. ${ }^{34}$ The occurrence of $L$.
braziliensis/L. peruviana hybrids in dogs and humans (Tables 1 and 2) from the same area indicates that both are exposed to the same infective sand fly population. This suggests that dogs might act as a reservoir host and enhance propagation of the emergent hybrid genotype.

Six zymodemes and at least 6 microsatellite genotypes were isolated from patients with MCL. Isolation of L. peruviana from a single case of MCL is an interesting finding but, in the absence of more cases, must be interpreted with caution. Previously in Peru, a single case of mucosal leishmaniasis (ML) was attributed to L. peruviana. ${ }^{1}$ Four of the MCL patients yielded a hybrid isolate, with no evidence of mixed infection, so patients carrying such isolates must be considered at risk of developing MCL. Thus, the finding of unequivocal genotypic markers for isolates that carry the risk of progression to MCL is still an elusive goal. ${ }^{35}$

As mentioned above, MLST applied to the L. donovani complex has already revealed the genetic basis of MLEE and provided a higher resolution approach to resolving genetic groups and to understanding relationships between them. ${ }^{25,30}$ MLMT has given even higher resolution of intraspecific population structure. ${ }^{10}$ Diversity of the subgenus L. (Viannia) is seen in some endemic foci, ${ }^{36}$ although the level observed in Huánuco is extraordinary. Genetic diversity has also been recorded from individual patients. ${ }^{37}$ Furthermore, it is apparent that there is some overlap of boundaries between the perceived species of the subgenus L. (Viannia). In combination, MLST and MLMT will be a powerful approach to understanding the complex molecular epidemiology and population genetics of L. (Viannia) and for further investigation of the extent of genetic exchange in natural or experimental populations. For the future MLMT of L. (Viannia), a much wider panel of microsatellite markers is required, and such a panel is in preparation ( $R$. Oddone, G. Schönian, and K. Kuhls, personal communication and unpublished data). In localities where L. (Viannia) species overlap, we anticipate the discovery and possible emergence of other human infective hybrid genotypes, some with potential to generate severe disease.

Received May 10, 2006. Accepted for publication October 31, 2006.

Acknowledgments: The authors thank Rachel Gregory (LSHTM) for technical assistance, David Conway (LSHTM), Helen Roberts (University College, London), and Isabel Mauricio (LSHTM) for helpful discussions. Dr. R. Naiff (Instituto Nacional de Pesquisas Amazonas, Manaus, Amazonas, Brazil) and Prof. J. Shaw (Instituto Evandro Chagas, Belém, Pará, Brazil) generously provided some of the reference strains used in this study.

Financial Support: This work was supported by European Commission International Scientific Co-operation (grant no. C11-CT93-0036NR), the Sir Halley Stewart Trust, and the Wellcome Trust.

Authors' addresses: Debbie Nolder, Clive R. Davies, and Michael A. Miles: Department of Infectious \& Tropical Diseases, London School of Hygiene \& Tropical Medicine, Keppel Street, London WC1E 7HT, United Kingdom, Telephone: +44 (0)20 7927 2427, Fax: +44(0)2076370268,E-mails: debbie.nolder@1shtm.ac.uk, clive.davies@1shtm.ac.uk, and michael.miles@1shtm.ac.uk. Norma Roncal: Instituto de Medicina Tropical "Alexander von Humboldt", Universidad Peruana Cayetano Heredia, AP5045, Lima 100, Peru, E-mail: nroncal@upch.edu.pe. Alejandro Llanos-Cuentas: Facultad de Salud Pública y Administración, Carlos Vidal Layseca, Universidad Peruana Cayetano Heredia, AP5045, Lima 100, Peru, Telephone: +511 482 7739/381 4100, Fax: +511 382 0338, E-mail: allanos@upch.edu.pe. 
Reprint requests: Debbie Nolder, Malaria Reference Laboratory, London School of Hygiene \& Tropical Medicine, Keppel Street, London WC1E 7HT, United Kingdom.

\section{REFERENCES}

1. Lucas CM, Franke ED, Cachay MI, Tejada A, Cruz ME, Kreutzer RD, Barrer DC, McCann SH, Watts DM, 1998. Geographic distribution and clinical description of leishmaniasis cases in Peru. Am J Trop Med Hyg 59: 312-317.

2. Guthman JP, Arlt D, Garcia LM, Rosales M, de Jesus Sanchez J, Alvarez E, Lonlas S, Conte M, Bertoletti G, Fournier C, Huari R, Torreele E, Llanos-Cuentas A, 2005. Control of mucocutaneous leishmaniasis, a neglected disease: results of a control programme in Satipo Province, Peru. Trop Med Int Health 10: 856-862.

3. Reithinger R, Espinoza JC, Llanos-Cuentas A, Davies CR, 2003. Domestic dog ownership: a risk factor for human infection with Leishmania (Viannia) species. Trans R Soc Trop Med Hyg 97: 141-145.

4. Llanos-Cuentas EA, Roncal N, Villaseca P, Paz L, Ogusuku E, Perez JE, Caceres A, Davies CR, 1999. Natural infections of Leishmania peruviana in animals in the Peruvian Andes. Trans $R$ Soc Trop Med Hyg 93: 15-20.

5. Brandao-Filho SP, Brito ME, Carvalho FG, Ishikawa EA, Cupolillo E, Floeter-Winter L, Shaw JJ, 2003. Wild and synanthropic hosts of Leishmania (Viannia) braziliensis in the endemic cutaneous leishmaniasis locality of Amaraji, Pernambuco State, Brazil. Trans R Soc Trop Med Hyg 97: 291-296.

6. Dujardin JC, Banuls AL, Llanos-Cuentas A, Alvarez E, DeDoncker S, Jacquet D, Le Ray D, Arevalo J, Tibayrenc M, 1995. Putative Leishmania hybrids in the Eastern Andean valley of Huanuco, Peru. Acta Trop 59: 293-307.

7. Grimaldi G Jr, Momen H, Naiff RD, McMahon-Pratt D, Barrett TV, 1991. Characterization and classification of leishmanial parasites from humans, wild mammals, and sand flies in the Amazon region of Brazil. Am J Trop Med Hyg 44: 645-661.

8. Evans DA, Godfrey D, Lanham S, Lanotte G, Modabber F, Schnur L, 1999. Handbook on Isolation, Characterization and Cryopreservation of Leishmania. UNDP/World Bank/WHO Special Programme for Research and Training in Tropical Diseases (TDR). Geneva, Switzerland: WHO.

9. Belli AA, Miles MA, Kelly JM, 1994. A putative Leishmania panamensis/Leishmania braziliensis hybrid is a causative agent of human cutaneous leishmaniasis in Nicaragua. Parasitology 109: 435-442.

10. Ostenreither S, Kuhls K, Schaar M, Presber W, Schőnian G, 2006. Multilocus microsatellite typing as a new tool for discrimination of Leishmania infantum MON-1 strains. J Clin Microbiol 44: 495-503.

11. Russell R, Iribar MP, Lambson B, Brewster S, Blackwell JM, Dye C, Ajioka JW, 1999. Intra and inter-specific microsatellite variation in the Leishmania subgenus Viannia. Mol Biochem Parasitol 103: 71-77.

12. Hartl DL, Clark AG, 1997. Principles of Population Genetics. Sunderland, MA: Sinauer Associates Inc.

13. Hedrick PW, 2004. Genetics of Populations. Third edition. Boston, MA: Jones and Bartlett Publishers Inc.

14. Maynard-Smith J, Smith NH, O'Rourke M, Spratt BG, 1993. How clonal are bacteria? Proc Natl Acad Sci USA 90: 43844388 .

15. MacLeod A, Turner CM, Tait A, 2001. The detection of geographical substructuring of Trypanosoma brucei populations by the analysis of minisatellite polymorphisms. Parasitology 123: $475-482$.

16. Gibson W, Whittington H, 1993. Genetic exchange in Trypanosoma brucei: selection of hybrid trypanosomes by introduction of genes conferring drug resistance. Mol Biochem Parasitol 60: 19-26.

17. MacLeod A, Tweedie A, McLellan S, Taylor T, Cooper C, Sweeney L, Turner CMR, Tait A, 2005. Allelic segregation and independent assortment in T. brucei crosses: Proof that the genetic system is Mendelian and involves meiosis. Mol Biochem Parasitol 143: 12-19.

18. Machado CA, Ayala FJ, 2001. Nucleotide sequences provide evidence of genetic exchange among distantly related lineages of Trypanosoma cruzi. Proc Natl Acad Sci USA 98: 7396-7401.

19. Gaunt MW, Yeo M, Frame IA, Stothard JR, Carrasco HJ, Taylor MC, Mena SS, Veazey P, Miles GA, Acosta N, de Arias AR, Miles MA, 2003. Mechanism of genetic exchange in American trypanosomes. Nature 421: 936-939.

20. Heitman J, 2006. Sexual reproduction and the evolution of microbial pathogens. Curr Biol 16: R711-R725.

21. Bennett RJ, Johnson AD, 2003. Completion of a parasexual cycle in Candida albicans by induced chromosome loss in tetraploid strains. EMBO J 22: 2505-2515.

22. Delgado O, Cupolillo E, Bonfante Garrido R, Silva S, Belfort E, Grimaldi Junior G, Momen H, 1997. Cutaneous leishmaniasis in Venezuela caused by infection with a new hybrid between Leishmania (Viannia) braziliensis and L. (V.) guyanensis. Mem Inst Oswaldo Cruz 92: 581-582.

23. Banuls AL, Jonquieres R, Guerrini F, Le Pont F, Barrera C, Espinel I, Guderian R, Echeverria R, Tibayrenc M, 1999. Genetic analysis of Leishmania parasites in Ecuador: are Leishmania (Viannia) panamensis and Leishmania $(V$.) guyanensis distinct taxa? Am J Trop Med Hyg 61: 838-845.

24. Kelly JM, Law JM, Chapman CJ, Van Eys GJ, Evans DA, 1991 Evidence of genetic recombination in Leishmania. Mol Biochem Parasitol 46: 253-263.

25. Mauricio IL, Silk R, Baghaei M, Yeo M, Pratlong F, Zemanova E, Dedet JP, Lukes J, Miles MA, 2006. Leishmania donovani complex: resolving genotypes and haplotypes for polymorphic metabolic enzymes. Int J Parasitol 36: 757-769.

26. Schwenkenbecher JM, Wirth T, Schnur LF, Jaffe CL, Schallig H, Al-Jawabreh A, Hamarsheh O, Azmi K, Pratlong F, Schönian $\mathrm{G}, 2006$. Microsatellite analysis reveals that population structure of Leishmania tropica exhibits both clonality and recombination. Int J Parasit 36: 237-246.

27. Ravel C, Cortes S, Pratlong F, Morio F, Dedet JP, Campino L, 2006. First report of genetic hybrids between two very divergent Leishmania species: Leishmania infantum and Leishmania major. Int J Parasitol.

28. Yeo M, Acosta N, Llewellyn M, Sanchez H, Adamson S, Miles GA, Lopez E, Gonzalez N, Patterson JS, Gaunt MW, de Arias AR, Miles MA, 2005. Origins of Chagas disease: Didelphis species are natural hosts of Trypanosoma cruzi I and armadillos hosts of Trypanosoma cruzi II, including hybrids. Int $J$ Parasitol 35: 225-233.

29. Zhang WW, Miranda-Verastegui C, Arevalo J, Mdao M, Ward B, Llanos-Cuentas A, Matlashewski G, 2006. Development of a genetic assay to distinguish between Leishmania (Viannia) species on the basis of isoenzyme differences. Clin Infect Dis 42: 801-809.

30. Zemanova E, Jirku M, Mauricio IL, Horak A, Miles MA, Lukes J, 2007. The Leishmania donovani complex: genotypes of five metabolic enzymes (ICD, ME, MPI, G6PDH, and FH), new targets for multilocus sequence typing. Int J Parasitol 37: 149160.

31. Jamjoom MB, Ashford RW, Bates PA, Chance ML, Kemp SJ, Watts PC, Noyes HA, 2004. Leishmania donovani is the only cause of visceral leishmaniasis in East Africa; previous descriptions of $L$. infantum and " $L$. archibaldi" from this region are a consequence of convergent evolution in the isoenzyme data. Parasitology 129: 399-409.

32. Torrico MC, De Doncker S, Arevalo J, Le Ray D, Dujardin JC, 1999. In vitro promastigote fitness of putative Leishmania (Viannia) braziliensis/Leishmania (Viannia) peruviana hybrids. Acta Trop 72: 99-110.

33. Almeida MC, Cuba-Cuba CA, Moraes MAP, Miles MA, 1996. Dissemination of Leishmania (Viannia) braziliensis. J Comp Pathol 115: 311-316.

34. de Moura TR, Novais FO, Oliveira F, Clarencio J, Noronha A, Barral A, Brodskyn C, de Oliveira CI, 2005. Toward a novel 
experimental model to study American cutaneous leishmaniasis caused by Leishmania braziliensis. Infect Immun 73: 58275834.

35. Garcia AL, Kindt A, Quispe-Tintava KW, Bermudez H, Llanos A, Arevalo J, Banuls AL, De Doncker S, Le Ray D, Dujardin JC, 2005. American tegumentary leishmaniasis: antigen-gene polymorphism, taxonomy and clinical pleomorphism. Infect Genet Evol 5: 109-116.

36. Rotureau B, Ravel C, Nacher M, Couppie P, Curtet I, Dedet JP,
Carme B, 2006. Molecular epidemiology of Leishmania (Viannia) guyanensis in French Guiana. J Clin Microbiol 44: 468473.

37. Cuervo P, Cupolillo E, Nehme N, Hernandez V, Saravia N, Fernandes O, 2004. Leishmania (Viannia): genetic analysis of cutaneous and mucosal strains isolated from the same patient. Exp Parasitol 108: 59-66.

38. Nolder D, 2000. Molecular Diversity in the Leishmania Subgenus Viannia. PhD thesis. University of London. 